\title{
Cognitive Motivation for Unaccusative Verbs with Objects in Existential Construction in Chinese
}

\author{
Haiying $\mathrm{Wu}$ \\ Foreign Languages College, Tianjin Polytechnic University, Tianjin, China \\ Ye Liang \\ Hebei Foreign Studies University, Shijiazhuang, China \\ Liling Tian \\ Foreign Languages College, Tianjin Polytechnic University, Tianjin, China
}

\begin{abstract}
This study applies conceptual blending and grammatical blending to analyze the meaning and structure construction of the NP1+Vi+NP2 construction in existential construction in Chinese. We found that the NP1+Vi+NP2 construction in existential sentences is the result of conceptual integration and grammatical blending of two subevents with basic grammatical structure of NP1+Vt+NP2 and NP2+Vi respectively. By discussing process of semantic construction and syntactic realization, we derive that the structure of existential sentences is integrated by the input spaces of "the existing object exists (or lies on some status)" and "somewhere exists something". It can concludes that the emergent meaning is "somewhere exists the existing object lying on some status" through analyzing the blending characters. This proves that conceptual integration and grammatical blending theories are animate and have mighty explanatory power in this specific linguistic phenomenon.
\end{abstract}

Index Terms - NP1+Vi+NP2, conceptual blending, grammatical blending

\section{INTRODUCTION}

The conceptual blending theory is based on mental space theory proposed by Gilles Fauconnier (1996). Conceptual blending occurs during on-line dynamic construction of full meaning. It involves two input spaces, a generic space, and a blended space and the emergent structure comes into being by mapping and projecting between different spaces. The basic operate mechanisms are composition, completion, and elaboration. Grammatical blending, one type of conceptual blending, is a model for the analysis of sentence generation and interpretation. Its syntactic realization of grammatical blending is represented from the syntactical structure based on the input spaces of conceived event and grammar construction by the mapping and projecting cross the spaces. And the semantic realization of grammatical blending is represented from the conceived event based on the input spaces of syntactical structure and grammar construction by the mapping and projecting cross the spaces.

This paper will use conceptual blending and grammatical blending to analyze the meaning and structure construction of the NP1+Vi+NP2 construction in existential construction.

\section{Distinctions Between Unergative Verbs and Unaccusative Verbs}

\section{A. Unaccusative Hypothesis}

Unaccusative Hypothesis was first proposed by Perlmutter (1978) in the frame work of Relation Grammar. There are two types of intransitive verbs: one is known as unaccusative verbs (e.g. happen, appear) and the other is known as unergative verbs (e.g. run, dance). The unaccusative verbs and unergative verbs are one-place verbs, however, the surface subject of an unaccusative verb is the logical deep object, the surface subject of an unergative verb is also the deep subject. Later, Williams (1981) and Burzio (1981) pointed out the two kinds of verbs both include a sole argument. The sole argument of an unaccusative verb is its internal argument, while the sole argument of an unergative verb is its external argument. According to Government and Binding Theory, the sentences with unaccusative verbs are regarded as those without objects in deep structures, whereas the sentences with unergative verbs are regarded as those without subjects in deep structures. With the frame work of RG, the difference between unaccusatives and unergatives is described as: the surface subject of an unergative verb is also the deep subject, whereas the surface subject of an accusative verb is the deep object.

Sportiche and koopman (1991) put forward VP internal Subject Hypothesis, which is a complement. They propose that the internal and external arguments are base-generated in VP, where can be assigned thematic roles. Therefore, the 
relationship between the internal and external arguments and V is local. In other words, the subject of an unergative verb is formulated in the position of specifier of VP in deep structure, whereas the subject of unaccusative verb is in the position of VP's complement. We will take (2) as an example.
(1) a. The girl runs.
(unergative)
b. The bus comes.
(unaccusative)

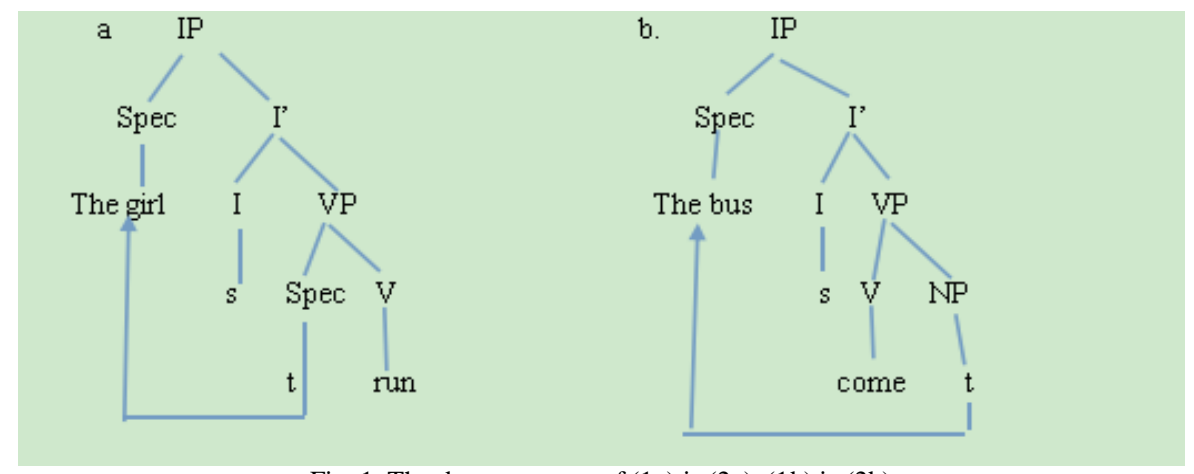

Fig. 1. The deep structure of (1a) is (2a), (1b) is (2b)

From the above examples, we can see in (1a), the subject "the girl" of the unergative verb "runs" is always the subject either in (1a) or (2a). But in (1b), the subject "the bus" of the unaccusative verb "comes" is the direct object in the deep structure of $(2 b)$.

So certain intransitive clauses are unaccusative clauses, which have subjects in the surface, but actually, take a final object in the deep structure. In Relational Grammar, the subjects of unergatives take the Specifier position at both D-structure and S-structure. However, unaccusative verb in the deep structure are in the position of D-structure, and after that, it may or may not move to the Specifier.

Permultter's UH is connected with impersonal passives in Dutch and Turkish. Permultter (1978) provides the list of English unergatives and unaccusatives.

Unergatives:

a. Verbs describing willed or volitional acts: run, dance, sing, talk, skate, swim, fight, bow, knock, hunt, bicycle, kneel, laugh, box, agree, etc.

b. Certain involuntary bodily processes: burp, vomit, sleep, cry, etc.

Unaccusatives:

a. Verbs expressed by some adjectives: big, small, red, black, etc.

b. Verbs whose subjects are semantically patient: sink, flow, rise, burn, hang, drown, trip, shake, wave, away, wave, float, slide, etc.

c. Aspectual verbs: start, begin, stop, end, etc.

d. Verbs of existing and happening: be, exist, live, dwell, stand, lie, remain, come, go, walk, fly, approach, appear, occur, arise etc.

From the above list, we may conclude that verbs represent volitional acts of the subjects and involuntary bodily processes of humans usually are unergatives. While, verbs represent nonvolitional events of the subject referents and show the changes of state are unaccusatives. In other words, unergatives take humans or animals as the subjects and usually describe volitional acts of their subject referents, so they are "do-type" expression. While, unaccusatives take inanimate as the subjects and usually describe changes of state, so they are "become-type" expression.

\section{B. Unaccusative Verbs in Chinese}

The above sections focus on the descriptions of unaccusative verb in English and other language, but not intensively on Chinese. Examples of unaccusative verb and unergative verb in Chinese can be shown in (Huang 2006). Examples of unaccusative and unergative verb are:

a. unaccusative verb: lai (come), qu (go), shi (is), you (have), si (die), tang (lie), zou(walk) chuxian (appear), fasheng (happen)......

b. unergative verb: xiao (smile), ku (cry), fei (fly), tiao (jump), chaonao (wrangle)......

Classification of unaccusative verb in Chinese, however, is not smooth, for one reason is, distinguishing transitive verb from intransitive verb in Chinese is not so easy to some extent. Unaccusativity, on the other hand, is said to be universals, which leads us to the discussion of unaccusaitive verb in Chinese specially. Generally, existential verb, non-causative verb and passive verb in Chinese are unaccusative verb. But such generation, is far from satisfaction. The lexical expression approach is cross-language different (Levin and Rappaport 1995:4), which may impact the judgement of a verb to be unaccusative verb or not. One type of such unaccusative verb is the combination of motion verb (generally monosyllable) and direction of moving, forming a kind of complex verb, such as verb+lai/qu/li/guo, meaning come/go/leave/pass, respectively, etc. As example (3) shows, the omission of the part of direction will lead to 
ungrammatical sentence.

This indicates that the parameter,[士 Direction], is a crucial factor in determining unaccusativity. We argue that the expression of lexical meaning in (4b) is similar to unaccusative verb in English as (3a) formed by Van Valin (1990).

(3) a. pa*(lai) 1e yi zhi ma-yi.

Crawl (come) LE one ant

(An ant crawls (over).)

b. Men-qian da-qiao xia you*(guo) yi qun ya

Door-front bridge under swim *(cross) one CL duck

(A group of ducks swim cross under the bridge in front of the door.)

(4) a.[x BECOME be-at]

b. [[x MOVE] BECOME be-at]

Another kind of unaccusative verb in Chinese as in example (3) is the so called alternative of intransitive verb and causative verb, which is the same to English. The only DP in (3b) obviously is internal argument, which confirms that the verb is an unaccusative verb, as we mentioned above. Such kind of verb generally indicates and shows a change of state, with the expression of lexical meaning in (4).

(5) a. Ta men chen 1e chuan

They sink ASP boat

(They made the boat sunk.)

b. Chuan chen le

Boat sink ASP

(the boat sank.)

(6) [x DO-something] CAUSE [y BECOME STATE]

The third kind of unaccusative verb in Chinese is verbs indicating appearance or disappearance, which is the same to English. The verb, si,(to die) in (7a), which indicates the disappearance of Wang Mian's father, is widely discussed in literature, is a typical example. Similarly, transitive verb when used as passive voice as in (7b) is also unaccusative verb. What is different from English is that two arguments, one external argument and the other internal argument which is often termed as retained object, can appear in the sentence.

(7) a. Wang Mian qi -sui shang si 1e fu-qin.

Name seven years old die ASP father.

b. LiSi bei tou le yi ge qian-bao.

Name Passive steal ASP one CL purse

(Li Si's purse was stolen.)

Similarly, almost the verbs, and especially derivation from adjective, or deadjectiveaed verbs, which indicates change of state, are unaccusative verbs in Chinese, though such verb will not used as causative verb in modern Chinese. It is noticeable that such verbs in Ancient Chinese are used widely as causative such as (8a) and (8b):

(8) a. Bei-zi po le.

Glass broke ASP

(Glass is broken.)

b. *Ta po le bei-zi.

He brake ASP glass

Intend (He broke the glass.)

c. Ta da po le bei-zi

He brake ASP glass

(He broke the glass.)

(9) a. Tou-fa hei le

Hair black ASP

(Hair turn black.)

b. ${ }^{* T a}$ hei le tou-fa

He black ASP hair

Intend (His hair turn black.)

\section{The Cognitive Analysis to the Existential Construction in Chinese}

\section{A. The Construction of Sentence Meaning}

From the type of conceptual blending, integrated network of existential sentences can be divided into two types. The first type is the existential sentences of double-scope network, including "zhe" construction, experiential aspect of existence sentences, progressive and complete aspect of dynamic existential sentences; The second type is the existential sentences of simplex network, including "you (have)" construction, "shi (be)" construction, centering predicate and noun predicate sentences. Then we'll discuss its meaning construction process.

a. Existential Sentences of Double-Scope Network 
The input space is the source space of the blended meaning. So in order to set up the conceptual blending meaning, input space must be established first. In general, the establishment of the unconventional sentence meaning is inseparable from conventional events expressed by the conventional sentence. Conventional events often rely on the general chronological order and the causal relationship in daily life to construct events. Conventional events provide the source concept for more complicated unconventional events. The syntactic form of existential sentences is "NP1 + V + NP2 ". The locative meaning is abstract and is usually a peripheral case. If location acts as a subject, the sentence is unconventional. The existence of specific acts as the subject may be more common.

Language form is the result of cognitive reflecting to the real world. Our cognition often focuses on the state of existence itself in the real world. We first perceive the state of existence, then to infer the existence's location. Basic cognitive sense also tells us that we first perceive something exists (appears or disappears) in a certain state, and then to know its location. That is to say, the concept "The existing object exists (appears or disappears) ." is the premise of the concept "Somewhere exists (appears or disappears) the existing object.". If people don't feel there exists (appears or disappears) something, then there is no concept of something exists (appears or disappears) somewhere. To express the meaning "Shu xia tang-zhe yi-ge-ren. There lays a person under the tree ", we should perceive first "yi-ge-ren tang-zhe. A person is lying", and then consider this man's location "under the tree". We establish the concept of "something" exists "under the tree", and then to produce the concept "There lays a person under the tree ". If we don't perceive "A person is lying", we can't set up the concept "There lays a person under the tree ". In order to express existential sentences "Mou-chu cun-zai (chu-xian huo xiao-shi) mou-wu. Somewhere exists (appears or disappears) something, we must first establish the construction "Mou-wu cun-zai(huo chu-yu mou-zhong-zhuang-tai). Something exists (or in certain state) "and then set up the concept of "Mou-chu cun-zai mou-wu. Somewhere exists something.", finally establish the existential meaning "Mou-chu cun-zai chu-yu mou-zhong-zhuang-tai de mou-wu. Somewhere exists something in certain state.", So the conceptual blending network of existential sentence meaning is as following:

Input space 1: The existing object exists (or in certain state).

Input space 2: Somewhere exists something

The blend: Somewhere exists the existing object in certain state.

In input space1, the object in a certain state is the specific form of existing object. When we know something in a certain state (such as standing, sitting, posting, swimming, etc.), we can infer the existence of the object, then putting the object's specific existing state (the object in a certain state)into the input space. Sometimes the object's specific existence state is unknown but only its existence is known, then input space can use the abstract form "The object exists." to express the meaning. Dynamic existential sentences and "zhe" construction, experiential aspect of existence sentences in static existential sentences can express specific existential state, while "you (have)" construction, "shi (be)" construction in static existential sentences, centering predicate and noun predicate sentences can't. In the former type, the input spacel can be " The existing object exists in a certain state." while the latter input space 1 is "The existing object exists.". Take sentence "Tai shang zuo zhe zhu-xi-tuan. The presidiums are sitting on the platform." as an example, its conceptual integration network is as follow:

Input space 1: zhu-xi-tuan zuo zhe. (The presidiums are sitting.)

Input space 2: Tai shang cun zai zhu-xi-tuan.(There exist presidiums on the platform.)

The blend: Tai shang zuo zhe zhu-xi-tuan. (The presidiums are sitting on the platform.)

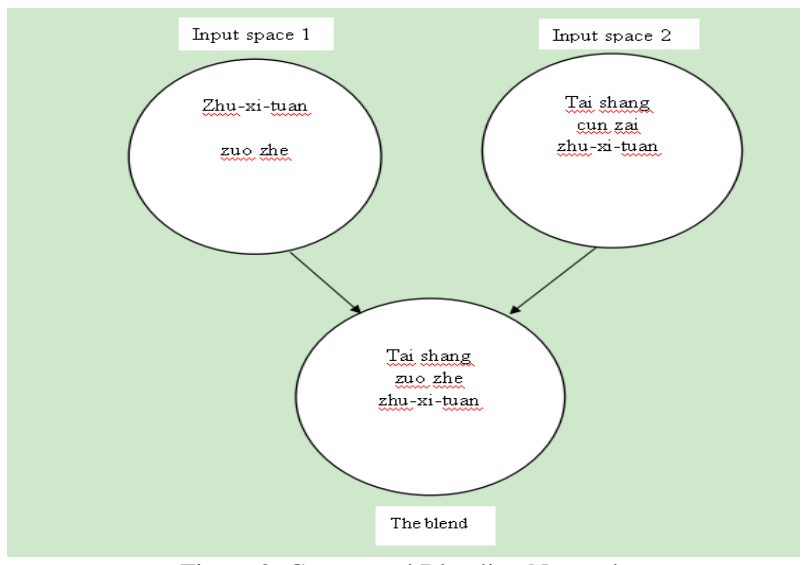

Figure 2. Conceptual Blending Network

The figure above shows that the events in input space 1 and 2 are related. The input space1 is state event and the input space 2 is existential event. There exists the mapping relation between the main body of the state event and the object in existential events. Both project to the blend forming the blended event. The structure relation of the blended event "zuo zhe (be sitting)" is derived from the state event, likewise, the choice of the event framework is at the mercy of human scale principles. Only the events closely related to human life and with a higher degree of significance can be as the framework for blended event. Blended event is the result of the concept projection in input space, and it consists 
part of the concept in the two input spaces. So the structure relation of the blended event must chose events with higher degree of significance to activate events with lower degree of significance. In this way can we integrate the two concepts into one concept. In general, concrete event is more significant than the abstract. And the dynamic event is more significant than static. Compared to the existential relation, state relation is concrete, existential relation is abstract, such as "zuo zhe (be sitting)" relative to "exist", the former is a specific posture, the latter is the abstract existential relation, obviously the former are more likely to be perceived. State relations are dynamic to some extent, such as "zuo (sit)" can indicate dynamic actions as well as the static state. Though in the existential sentence "zuo zhe (be sitting)" is a kind of non-moving state and has the characteristics of attachment, it is a static state after moving action. So the state relation is more dynamic compared to the abstract existential relation. The state relations are more significant than the existential relation, thus it is more suitable to be the events framework for the blend space. So "Tai shang zuo zhe zhu-xi-tuan. The presidiums are sitting on the platform." can express the meaning "On the platform the presidiums exist by means of sitting", while "Tai shang cun zai zhu-xi-tuan. On the platform the presidiums exist." can't express the meaning. That's because the former's significance activates the nonsignificant relation, so as to integrate the input space, while the latter can't, thus fails to integrate.

We can see the above frame network is Double-Scope Network. Double-Scope Networks' input spaces own different framework. Part of the framework in this two input Spaces can be projected into the blend, forming unique framework in blended space. In double-scope networks, the framework of both input space plays an important role in integrating framework.

\section{b. Existential Sentences of Simplex Network}

"Shi(be)"construction, "you(to have)" construction, the centering predicate sentences and the noun predicate sentences set up meaning in a slightly different way. These sentences are blended with simplex networks which is the simplest frame network. In simplex networks the abstract framework composes an input space, some specific filling elements compose another input space. The integrated framework merges framework and the specific value in input space with the simplest way. Existential sentence in input space 1 "Mou-chu cun zai (chu-xian huo xiao-shi) cun-zai-dui-xiang. (Somewhere exists (appears or disappears) the existing object.)" blends with the specific value in space 2. For example, the sentence "Shan xia you fang-zi. There is a house down the hill " forms corresponding relationship by "Mou-chu cun zai cun-zai-dui-xiang (Somewhere exists the existing object.)" and "Shang xia you fang-zi. (There is a house down the hill)". Both build mapping relation in the blend, "shan xia (down the hill)" namely "somewhere", "you (have)" namely "exist" and "fang-zi (house)" namely "the existing object".

\section{B. Blending Characteristics of Sentence Patterns}

\section{Structure of Existential Sentence}

Segment A

The Structure of existential sentence is "NP1+V+NP2 ". According to Fan Fanglian (1963), the structure is divided into segments A, B, C. Segment A is location which generally composed nouns of places or nouns with preposition. Sometimes a prepositional phrase can used in segment A.

(10) a. Zai zuo zi shang you yi-ben-shu.

on the table have a book

(There is a book on the table.)

b. Cong qian mian chuang guo lai yi-ge-ren.

from the front come a person

(A person came from the front.)

The sentence is still valid after removing preposition of the prepositional phrase above. Sometimes the time component can be used in segment A, for example "Zuo tian lai le yi wei ke-ren. A guest came yesterday". A section of the composition of existential sentences more freedom, so the component of segment A is very free.

Segment B

Components of segment $\mathrm{B}$ are existential verbs, including two types: one is abstract non-motional verb, such as "you (have)" and "shi (be)"; another is action verb denoting state or manner of movement, such as verbs "zhan (stand), tang (lie), tie (stick to), fei (fly)", etc. The research to existential verb from the perspective of the semantic features has yielded fruitful results (Zhu Dexi 1981; Lu Jianming 1991; Qi Huyang 1998), but the research to its combination function is not comprehensive. Here the existential verbs' integration features is mainly shown by researching the nature of verb and combination function, and you can see the components of segment B in existential sentences have more restrictions, such as:

The action verbs of existential sentences only show abstract existential state, it is different from the general verbs with "agent-patient" relations. Although the existential verbs have controllable (or volitional) verbs, but the autonomy of controllable verbs is restrained. It can only indicate existential state. Such as the meanings between sentences "Di shang reng le yi-ge yan-tou. There threw a cigarette butt on the ground" and "Ta ren le yi-ge yan-tou. He threw a cigarette butt." are different obviously. The former is a kind of existential state, the latter is an active action. Existential verbs do not have the initiative. So the verb can't overlap because the overlapping verbs mean trying actively. When it adds adverbials of possibility in front of the verbs, the initiative verbs "bi xu (must)" can't be used in the sentence while 
others words can. Desiderative or subjective verbs will conflict with the objective existential meaning, so it can't be used in existential sentences. When it adds adverbials of frequency in front of the verbs, "jing chang (often), "you (again)" can be used in existential sentences but "zai (again)"can't. For "often"is routine action, "you (again)" indicates completed action while "zai (again)" indicates the actions unrealized. And existential sentences can only indicate existential meaning which is objective, progressive or completed, but not the action unrealized. When it adds adverbials of time in front of the verbs, progressive or completed words can be used in the sentence as well, while "ma shang (Immediately)" can't. When it adds descriptive words in front of the verbs, there are two different cases. If the descriptive words express the objective existential state, then it is valid. If it indicates subjective state, it will be restricted. For example, "*Tai-shang duan-duan-zheng-zheng-de zuo zhe zhu-xi-tuan (The presidiums are sitting as straight on the platform)." The Chinese sentence is not valid because the verb can't be modified by the subjective word.

In a word, verbs in segment B can only express abstract, objective, existential meaning, all the subjective, unrealized and descriptive verbs can't be used in the existential sentence.

Segment $C$

Component of segment $\mathrm{C}$ is existential object, it can be things, individuals and abstract ideas, such as sentences " Xin li you ge yuan-wang (*have a desire in heart).", "Nao hai yi pian kong-bai( *mind goes blank)". Existential object can be modified freely by quantifiers, such as "Chuang shang tang zhe yi-ge-bing-ren (There lies a patient on the bed.)", "Chuang shang tang zhe bing-ren (There lies a patient on the bed)." are all valid. The form of segment C component is very free, it can also be modified by descriptive attribute, time attribute and possessor attribute.

\section{The Emergent Meaning of Sentence Pattern}

\section{Blending Features Analysis}

Emergent meaning is the blended concept formed by input space concept projecting to the blend. It is different from the input space concept. Composition, completion, and elaboration lead to emergent meaning in the blend. Emergent meaning is not explicit meaning that can be perceived directly. There are two ways to infer it. The first way is to deduce it through the blend characteristics. The blend characteristics are its surface appearance. The second way is to deduce it through the integration process because the integration process can infer the meaning' construction process. Then the blend characteristics and the integration process will be applied to deduce the emergent meaning of the sentence.

There's no conspicuous difference between components of segment A, segment $\mathrm{C}$ and the general nouns in existential sentences. Segments B have many restrictions and have obvious characteristics of integration. Verbs in segment B can only express abstract, objective, existential meaning, all the subjective, unrealized and descriptive verbs can't be used in the existential sentence. It is shown as follows:

1. Objectivity. From the perspective of subjectivity and objectivity, the existential sentences express the objective fact. The structure "NP1+V+NP2" takes the location as its topic, and passes information with the existential object. It illustrates meaning that somewhere exists (appears or disappears) something.

2. Unwillingness. The existential sentences express reality. There's no subjective emotion of the existential object. Therefore desiderative verbs, the negative adverbs of subjective intention and the reduplicate form of verbs can't be used in the sentences.

3. Completion. From time aspect, the existential sentences mostly express the progressive fact or the fact that has happened. It can't express the actions that does not happen. For example,

a. Chuang-shang tang le yi-ge-ren. bed on lie ASP a person

(There lay a person on the bed.)

b. *Chuang-shang ma-shang tang le yi-ge-ren. bed on immediately lie ASP a person

c. * Chuang shang jiang yao tang yi-ge-ren. bed on will lie a person

d.* Chuang shang ming tian tang yi-ge-ren. Bed on tomorrow lie a person

4. Nondescriptiveness. The verbs in existential sentences can't be modified by adjectives, while the existential object can. For example,

a. Qiang-shang gong-gong-zheng-zheng-de xie zhe ji-ge-zi. wall on neatly write ASP a few words

(There are a few words written neatly on the wall.)

b. *Qiang-shang ren-ren-zhen-zhen-de xie zhe ji-ge-zi. wall on seriously write a few words

Actually "gong-gong-zheng-zheng (neat)" modifies the existential objects "a few words", the sentence is valid. While "ren-ren-zhen-zhen" modifies the verb "write", so the sentence is not valid.

In fact, those four characteristics above is associated with each other. Subjectivity, willingness, possibility, descriptiveness are interrelated entity. Subjective angle of view, of course, consists of willingness. Feelings subjective intention can express the state of possible emotion. Objectivity, unwillingness, completed and progressive events are interrelated entity as well. From the objective point of view, it absolutely don't consists of willingness. According to the 
characteristics of integration analysis, we can deduce the structure of existential sentences: Mou-chu cun zai(chu-xian huo xiao-shi) mou-ren(mou-wu)( there exists (appears or disappears) something or somebody at someplace).

What's more, in existential sentences, "zuo" (zuo)-kind intransitive verbs and "cun zai" share the common semantic feature of [+existence] and "zuo" (zuo)-kind intransitive verbs add concrete meaning to the abstract meaning of "cun zai" (how it exists). The most conventional ways of living/existing can last for a long time and show a lasting state.

\section{Blending Process Analysis}

The concept of existential sentence is derived from "The objects exist (or in certain state)." and "There exist some objects at someplace." In the integration it is merged by choosing the relation framework of the former and the composition order of the latter. The blending process is achieved by composition, completion and elaboration. Blending can compose elements from the input spaces to provide relations that do not exist in the separate inputs. When the two input spaces blend, the existential objects of the two input spaces yield mapping relation because of their identity. By blending people can correlate the concept "There exists something at someplace." with "Something exists in certain state.", thus yielding the blended meaning "There exists something in certain state at someplace”. But in order to run the mapping relation of the two spaces, we need activate the background information about the existential object. Only when the imaged object agrees with the object we familiar in our background knowledge can we blend the two spaces. Existential object can decide whether existential sentences are valid or not. For example:

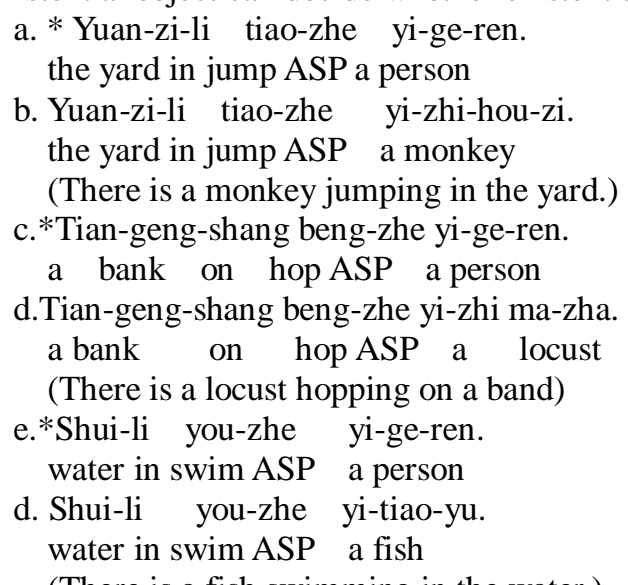

(There is a fish swimming in the water.)

Ren Ying (2009) believes that the verbs in existential sentence are abstract meaning rather than a specific action. So the verbs should denote the existing state of the existential object. The verbs “jump, hop, swim" aren't the conventional movement of man, but those motions are some animals' conventional movement. So that is the reason why sentences a,c ,e are invalid. Ren Ying's viewpoint can illustrate the reason why those sentences are valid, but he can't explain why the conventional movement of the existential object can be established. We can get the answer from the cognitive mechanism of the blending process. The conventional movement or the normal existential way of the object can activate the objects' identity in two different input spaces which is connected to long-term schematic knowledge. Thus it yields the mapping relation with the same object from the input structures "There exists something at someplace." and "Something exists in certain state." It is the role of gestalt psychology the blending meaning can be set up. Take sentences "*Yuan-zi-li tiao-zhe yi-ge-ren. A person jumps in the yards." and "Yuan-zi-li tiao-zhe yi-zhi-hou.-zi. There is a monkey jumping in the yard." for example. The input spaces of the former are "The yard exist a person." and "A person jumps." Because the verb "jump" isn't the conventional movement, it is hard to take the individual in "The yard exist a person." and the individual in "A person jumps." as the same person. So we can't blend the meaning "Yuan-zi-li cun-zai-zhe tiao-zhe-de ren. There exists a person jumping in the yard." But if it comes to monkey, it is easy to blend the existential objects into one because "jump" is the conventional movement of monkey. Thus we can set up the blend meaning "Yuan-zi-li cun-zai-zhe tiao-zhe-de hou-zi. There exists a monkey jumping in the yard."

\section{Generation Mechanism of Sentence Meaning and Syntactic Realization}

\section{Generation Mechanism of the Sentence Meaning}

The construction of sentence meaning is achieved by setting up conceptual blending framework to blend the emergent meaning. That means the language forms "NP1+V+NP2" can activate the human brain to set up the concept "Somewhere exists something." and "Something exists in certain state." These two concepts build mapping relation and project to the blend forming the emergent meaning "Somewhere exists something in certain state." The generation of the emergent meaning experiences the following steps: (take "Tai-shang zuo-zhe zhu-xi-tuan. The presidiums are sitting on the platform." as an example)

1. In sentence "Tai-shang zuo-zhe zhu-xi-tuan. (The presidiums are sitting on the platform.)", the location phrase is the subject. It is a unconventional sentence, and it doesn't agree with the routine events that people familiar. Then it will activate the brain to construct a new concept framework. Because "zuo (sit)" is man's conventional action, according to the meaning and experience people can infer that "zuo zhe (be siting)" is the presidium's state rather than the action 
"tai-shang (on the platform)" does. Thus the concept "zhu-xi-tuan zuo-zhe (the presidiums are sitting))" is set up in input space 1. "Tai-shang (the platform)" is the presidiums' conventional location. Then the concept "Tai-shang cun-zi zhu-xi-tuan. (There exist the presidium)" is set up in input space 2 .

2. The sentences"Zhu-xi-tuan zuo-zhe. (The presidium are sitting.)"and "Tai-shang cun-zai zhu-xi-tuan. (There exist the presidium on the platform.)" will run the structure and relation mapping. Through the background knowledge we can be sure that the presidium in this two spaces own identity relation, thus setting up mapping relation between them.

3. The sentences"Zhu-xi-tuan zuo-zhe. (The presidium are sitting.)"and "Tai-shang cun-zai zhu-xi-tuan. (There exist the presidium on the platform.)" combine with each other. Based on the background knowledge and gestalt psychology theory, we blend the structures and the relations of the concept, then forming the blending meaning "Tai-shang zuo-zhe zhu-xi-tuan. (The presidiums are sitting on the platform.)".

Syntactic Realization of the Sentence Structure

Syntactic realization of the sentence structure is a process from meaning to syntax. Grammatical blending is the method to syntactic realization of the existential sentence. Grammatical blending is achieved through similarities between conceived events and grammatical structure. They are merged in the blend and are reflected over the syntactic structure. For the conceived events and grammatical structure share similarity and relevance, this prompts those two to set up mapping relation. The structure of existential sentence is formed by blending the conceived event and the syntactic structure.

In general, the conceived events and the concepts of the input spaces are correspond with each other. So the conceived events of the existential sentences are the concepts "Cun-zai dui-xiang cun-zai (huo chu-yu mou-zhong zhuang-tai). The existing object exists (in a certain state)." and "Mou-chu cun-zai cun-zai-dui-xiang. There exists the existing object at someplace." The grammatical structure is normally correlates with the emergent meaning. The existential sentence's grammatical structure is "Mou-chu cun-zai (chu-xian huo xiao-shi)(chu-yu mou-zhong zhuang-tai)cun-zai-dui-xiang. There exists (appears or disappears) the existing object (in certain state) at someplace." Its syntactic realization process is in the following:

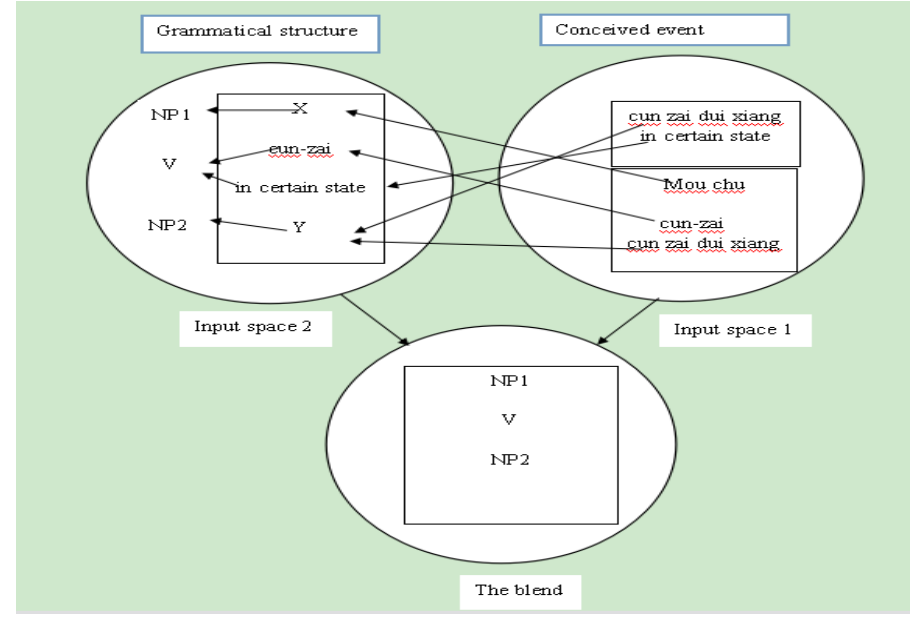

Figure 3. Syntactic Realization

Take "Tai-shang zuo-zhe zhu-xi-tuan. The presidiums are sitting on the platform" as an example.

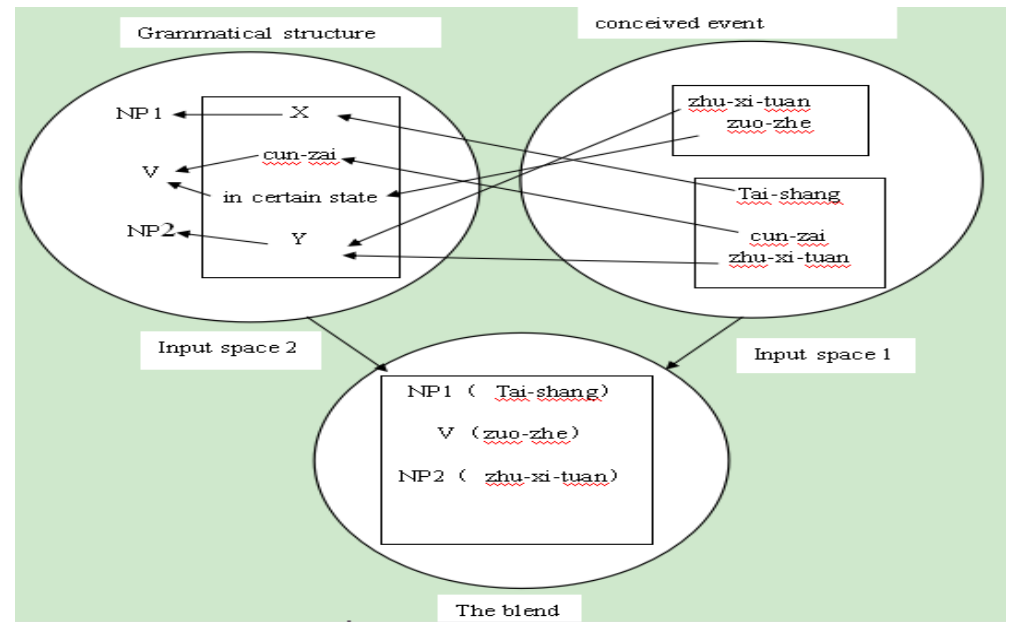

Figure 4. The Syntactical Realization of "Tai-shang zuo-zhe zhu-xi-tuan. The presidiums are sitting on the platform". 
From the above figure we see that the conceived events are "Zhu-xi-tuan zuo-zhe. (The presidiums are sitting.)" and "Tai-shang cun-zai zhu-xi-tuan. (There exists the presidium on the platform.)". Its grammatical structure is "X cun-zai (mou-zhong zhuang-tai-de) Y." The conceived event and the grammatical structure set up the mapping relation based on the similarity and the relevance. The conceived event "zhu-xi-tuan (the presidiums)" is mapped to "Y". "zuo-zhe (be sitting)" is mapped to "chu-yu mou-zhong zhuang-tai (in certain state)" "tai-shang (on the platform)" maps to "X". "cun-zai (exist)" maps to "cun-zai (exist)". The conceived event and the grammatical structure then map to the syntactic form. " $\mathrm{X}$ " in the grammatical structure projects to "NP1" in syntactic form. "cun-zai (exist)" and"chu-yu mou-zhong zhuang-tai (in certain state)" project to "V". "Y" projects to "NP2". The specific component in the conceived event "tai-shang (on the platform)" projects to "NP1", "zuo-zhe (be sitting)" to "V", and "zhu-xi-tuan (the presidium)" to "NP2", forming the syntactic form "Tai-shang zuo-zhe zhu-xi-tuan. The presidiums are sitting on the platform".

\section{CONCLUSION}

It is found that NP1+Vi+NP2 construction in existential sentences and sentences of possessum-object construction is a result of conceptual integration and grammatical blending of two subevents with basic grammatical structure of $\mathrm{NP} 1+\mathrm{Vt}+\mathrm{NP} 2$ and NP2+Vi respectively. In addition, the study has proved that conceptual integration and grammatical blending theories are animate and have mighty explanatory power in this specific linguistic phenomenon. By discussing the process of semantic construction and syntactic realization, we derive that the structure of existential sentences is integrated by the input spaces of "the existing object exists (or lies on some status)" and "somewhere exists something". It can concludes that the emergent meaning is "somewhere exists the existing object lying on some status" through analyzing the blending characters. Sentences of possessum-object construction are blended by "Possessor gets or loses possessee." and "Possessor appears or disappears." Its emergent meaning is "Possessor appears or disappears possessee."

\section{ACKNOWLEDGMENTS}

The author acknowledges financial support from China Tianjin Philosophy and Social Science Project (TJWW15-019). Thanks also go to Li Dongjie and Zhang Jinzhu for their support and great ideas.

\section{REFERENCES}

[1] Burzio, L. (1981). Intransitive verbs and Italian auxiliaries. Doctoral Dissertation. MIT, Cambridge, Massachusetts.

[2] Fan Fanglian. (1963). The existential sentence. Studies of The Chinese Language, 5, 386-395.

[3] Fauconnier, G. \& E. Sweetser. (1996). Spaces, worlds and grammar. Chicago: University of Chicago Press.

[4] Huang, C.-T. James. (2006). Resultatives and unaccusatives: a parametric view. Bulletin of the Chinese Linguistic Society of Japan, 253,1-43.

[5] Koopman, H \& D. Sportiche. (1991). The position of subjects. Lingua, 85, 211- 58.

[6] Levin, B. \& M. Rappaport Hovav. (1995). Unaccusativity: At the Syntax-Lexical Semantics Interface. Cambridge, MA: The MIT Press.

[7] Lu Jianming. (1991). The Application of semantic feature analysis in Chinese grammar studies. Chinese Language Learning, 1, $1-10$.

[8] Perlmutter, D. (1978). Impersonal passives and the unaccusative hypothesis. Berkeley Linguistics Society, 4, 157-189.

[9] Qi Huyang. (1998). The Studies on Space Problems in Modern Chinese. Shanghai: Academia Press.

[10] Ren Ying. (2009). How the sentence Wán Miăn Sǐle Fùqin is genarated? --From the correlation of concepts to that of construction. Chinese Teaching in the World, 3, 308-321.

[11] Van Valin D. (1990). Semantic parameters of split intransitivity. Language, 66, 221-260.

[12] Williams, E. (1981). Argument structure and morphology. The Linguistic Review, 1, 81-114.

[13] Zhu Dexi. (1981). "Writing on the Blackboard" and related sentence structure. Language Teaching and Linguistic Studies, 1, 4-18.

Haiying Wu was born in Shandong, China. She completed a Doctor's degree in linguistics and applied linguistics in Minzu University of China. She got a Master's degree in English language and literature in Shandong Normal University, China. She has been teaching English as a full-time associate professor for 14 years. Her main research interests are studies of language and culture, academic teaching and studies and the application of Chaos theory in linguistic studies. She has published: Wu Haiying. (2016). The Cultural Cognition of Numeral Metaphor in English and Chinese. Guangzhou: World Publishing Corporation, Guangdong Branch. She also published more than 10 papers in linguistic journals. Wu Haiying is currently teaching in foreign languages college, Tianjin Polytechnic University, China.

Ye Liang was born in Hunan, China in 1989. She graduated from Foreign Languages College of Tianjin Polytechnic University with a master's degree of Arts in 2015. Currently she works in He Bei Foreign Studies University, Shijiazhuang, China. 
Liling Tian was born in Henan, China in 1979. She graduated from Henan Normal University with a master's degree of Arts in 2005. Currently she works as a lecturer in Foreign Languages College of Tianjin Polytechnic University. Her research interests include teaching methods and literature. 